\title{
Mild oxidative stress induced by a low dose of cisplatin contributes to the escape of TRAIL-mediated apoptosis in the ovarian cancer SKOV3 cell line
}

\author{
JINZHI LU ${ }^{1}$, LEI ZHANG ${ }^{2}$, FANG XIE ${ }^{2}$, LIYA ZHU $^{2}$, XIAOLAN LI ${ }^{3}$, JINGPING OUYANG $^{4}$, \\ XIAOHUA HE ${ }^{4}$, SONG HAN ${ }^{4}$ and CUNJIAN $\mathrm{YI}^{2}$ \\ Departments of ${ }^{1}$ Laboratory Medicine and ${ }^{2}$ Obstetrics and Gynecology, Jingzhou First People's Hospital, Jingzhou, Hubei; \\ ${ }^{3}$ Department of Obstetrics and Gynecology, Yichang Second People's Hospital, Yichang, Hubei; \\ ${ }^{4}$ School of Basic Medical Sciences, Wuhan University, Wuhan, Hubei, P.R. China
}

Received November 2, 2015; Accepted March 1, 2016

DOI: $10.3892 /$ or.2016.4702

\begin{abstract}
Tumor necrosis factor (TNF)-related apoptosis-inducing ligand (TRAIL) is expressed in ovarian tissue and is widely thought to exhibit strong antitumor activity in a variety of tumor cell types. Therefore, we hypothesized that the cisplatin resistance of ovarian cancer is linked to the ability to escape from TRAIL-mediated apoptosis. We demonstrated that cisplatin-resistant ovarian cancer cell line SKOV3/DDP tolerated treatment with TRAIL, in contrast to the cisplatin-sensitive ovarian cancer cell line SKOV3. SKOV3/DDP cells exhibited a much higher cell viability and a lower apoptosis rate than SKOV3 cells after treatment with TRAIL. To determine whether cisplatin induced the tolerance of TRAIL, we pretreated the SKOV3 cells with cisplatin in the presence of TRAIL. This revealed that a low dose of cisplatin $(1 \mu \mathrm{M})$ increased the TRAIL tolerance of SKOV3 cells. Furthermore, cisplatin induced oxidative stress in both the SKOV3/DDP and SKOV3 cells, although the oxidative stress level of the SKOV3/DDP cells was generally much higher than that noted in the SKOV3 cells. Similarly, a low dose of hydrogen peroxide increased the TRAIL tolerance in SKOV3 cells. Notably, the TRAIL tolerance in the SKOV3 and SKOV3/DDP cells could be abrogated by the oxidative stress scavenger $N$-acetyl-cysteine. These results suggest that a low dose of cisplatin induces the tolerance of TRAIL in SKOV3 cells at least partly, depending on the oxidative stress signaling pathway.
\end{abstract}

Correspondence to: Dr Cunjian Yi, Department of Obstetrics and Gynecology, Jingzhou First People's Hospital, Jingzhou, Hubei, P.R. China

E-mail: cunjiany@163.com

Dr Jinzhi Lu, Department of Laboratory Medicine, Jingzhou First People's Hospital, Jingzhou, Hubei, P.R. China

E-mail: jinzhilu2015@163.com

Key words: cisplatin resistance, oxidative stress, TRAIL, ovarian cancer, SKOV3 cells

\section{Introduction}

Chemotherapeutic agents such as cisplatin are an important means of adjuvant therapy for the treatment of patients with ovarian cancer. The major drawback, however, is the development of drug resistance. Tumor necrosis factor (TNF)-related apoptosis-inducing ligand (TRAIL) is a type of cytokine produced and secreted by many tissues and cells including ovarian tissue (1). It is widely thought to have strong antitumor activity in a variety of tumor cell types (1-3). Therefore, we hypothesized that cisplatin-resistant ovarian cancer cells are able to escape from TRAIL-mediated apoptosis. According to this, TRAIL tolerance would be a potential limitation in the treatment of cisplatin-resistant ovarian cancer, and the elucidation of the mechanism leading to TRAIL tolerance may be an important therapeutic target for the treatment of cisplatin-resistant epithelial ovarian cancer.

Solid cancer tumors can develop cisplatin resistance, which may be mainly linked to the fact that only a low dose of cisplatin is able to penetrate into the depth of the tumor (4-7). To prove that TRAIL tolerance is linked to cisplatin resistance, it needs to be ascertained whether TRAIL tolerance can be induced by a low dose of cisplatin. Furthermore, the functional role of TRAIL and the mechanisms of TRAIL tolerance require elucidation. Recently, cisplatin has been proven to produce oxidative stress in vivo and in vitro (8-10). Some research groups have demonstrated that different levels of oxidative stress can determine cancer cell fate (11-14). According to these reports, mild oxidative stress promotes cell viability, whereas high oxidative stress induces cell death in a variety of tumor cell types. Therefore, we hypothesized that TRAIL tolerance may be associated with mild oxidative stress mediated by a low dose of cisplatin, which is already supported by evidence. For example, Xia et al detected high levels of reactive oxygen species (ROS) and much higher levels of NADPH oxidase Nox4 in ovarian cancer cells (15). Some authors have suggested that oxidative stress production during ovarian cancer progression may contribute to tumorigenicity and chemoresistance of human ovarian cancer cells $(16,17)$. Furthermore, early transformative changes in normal ovarian surface epithelium are 
possibly induced by oxidative stress (18). Recently, it has been demonstrated that oncogene-transformed epithelial cancer cells show a significant increase in mitochondrial mass, which is strictly dependent on oxidative stress (19). In addition, the generation of ROS has been reported to contribute to resistance to TRAIL-mediated apoptosis in human astrocytoma cells (20). However, increasing oxidative stress has been identified to improve TRAIL sensitivity in ovarian cancer cell lines (21). Some groups have furthermore confirmed that oxidative stress promotes the apoptosis of cancer cells $(22,23)$. A variety of natural and synthetic compounds such as LY35001, wogonin, and diallyl polysulfides were found to be capable of increasing the intracellular hydrogen peroxide level and potentiating TRAIL cytotoxicity toward different human malignant cells (24-27). Thus, remaining questions are: whether cisplatin resistant-ovarian cancer cell lines are tolerant to TRAIL exposure, and which functions different levels of cisplatin-mediated oxidative stress exert on TRAIL chemotherapy in epithelial ovarian cancer cells.

In the present study, we demonstrated that the cisplatin-resistant ovarian cancer cell line SKOV3/DDP is tolerant to TRAIL, in contrast to the cisplatin-sensitive ovarian cancer cell line SKOV3. However, a low dose of cisplatin resulted in TRAIL tolerance in SKOV3 cells, which was ascribed to the production of mild oxidative stress. This was confirmed by the observation that SKOV3/DDP cells exhibited much higher levels of oxidative stress than SKOV3 cells, and that the oxidative stress scavenger $\mathrm{N}$-acetyl-cysteine (NAC) could reverse the cisplatin-induced tolerance of TRAIL in the SKOV3 and SKOV3/DDP cells. Taken together, these results showed that mild oxidative stress resulting from exposure to a low dose of cisplatin contributes to the escape of TRAIL-mediated apoptosis in the SKOV3 cell line.

\section{Materials and methods}

Cells and reagents. SKOV-3 and SKOV-3/DDP cells were purchased from the Shanghai Cellular Research Institute (Shanghai, China) and maintained in RPMI-1640 medium supplemented with $10 \%$ fetal bovine serum (both from Hyclone, USA), $100 \mathrm{U} / \mathrm{ml}$ penicillin and $100 \mu \mathrm{g} / \mathrm{ml}$ streptomycin at $37^{\circ} \mathrm{C}$ in a humidified atmosphere of $5 \% \mathrm{CO}_{2}$. The cells were trypsinized at $80 \%$ confluency with $0.25 \%$ trypsin/0.02\% EDTA in Hank's solution for 1-3 min and resuspended in a complete culture medium. Recombinant human TRAIL/Apo2L was purchased from PeproTech (London, UK). cis-Diammineplatinum(II) (cisplatin), $N$-acetyl-cysteine (NAC) and hydrogen peroxide $\left(\mathrm{H}_{2} \mathrm{O}_{2}\right)$ were obtained from Sigma (St. Louis, MO, USA). CM- $\mathrm{H}_{2}$ DCFDA was purchased from Invivogen (San Diego, CA, USA). Annexin V-FITC apoptosis kits were obtained from BD Pharmingen (San Diego, CA, USA). 3-(4,5-Dimethyl-2-thiazolyl)-2,5-diphenyl2-H-tetrazolium bromide (MTT) was purchased from Sigma.

MTT assay. Cell viability was determined using the MTT assay. Near-confluent SKOV3 and SKOV3/DDP cells were seeded on a 96-well plate in $100 \mu \mathrm{l}$ of RPMI-1640 medium supplemented with cisplatin $\left(1,10 \mu \mathrm{M}\right.$; Sigma) or $\mathrm{H}_{2} \mathrm{O}_{2}(0.1$, $1 \mathrm{mM})$ for the indicated time. Cisplatin $(1,10 \mu \mathrm{M})$ or $\mathrm{H}_{2} \mathrm{O}_{2}$ $(0.1,1 \mathrm{mM})$ treatment was chosen in the present study since
$1 \mu \mathrm{M}$ cisplatin and $0.1 \mathrm{mM} \mathrm{H}_{2} \mathrm{O}_{2}$ have no effects on apoptosis which are different from $10 \mu \mathrm{M}$ cisplatin and $1 \mathrm{mM} \mathrm{H}_{2} \mathrm{O}_{2}$ (data not shown). Next, the medium was removed and replaced with $10 \mu 1$ reconstituted MTT in the RPMI-1640 medium. The plate was then incubated under standard incubation conditions for $2 \mathrm{~h}$. After the incubation period, the culture fluid was removed. This was followed by the addition of $100 \mu$ l MTT solubilization solution, and the plate was placed on a mini-shaker for 10 min to assist in dissolving the crystals. The absorbance was read at a wavelength of $570 \mathrm{~nm}$ and the background at $655 \mathrm{~nm}$.

Analysis of apoptosis. Apoptosis was analyzed using Fluorescence-Activated Cell Sorting (FACS). After $1 \times 10^{5}$ cells/well of SKOV3 and SKOV3/DDP cells were seeded on a 6-well plate for $24 \mathrm{~h}$, the cells were treated with or without cisplatin $(1,10 \mu \mathrm{M})$ and/or TRAIL (500 $\mathrm{ng} / \mathrm{ml})$ for the indicated time. The current treatment of TRAIL was used in the present study according to a previous study (20). Then, the cells were harvested, washed with PBS, and stained with FITC-Annexin V (Sigma) and propidium iodide (PI). Cell apoptosis was analyzed by flow cytometry using CellQuest ${ }^{\mathrm{TM}}$ software.

Measurement of reactive oxygen species generation. 5-(and-6)-Chloromethyl-2',7'-dichlorodihydrofluorescein diacetate, acetylester (CM- $\mathrm{H}_{2}$ DCFDA; Invivogen) was deacetylated by intracellular esterase to the non-fluorescent DCFH, which can be oxidized by ROS to the fluorescent compound 2',7'-dichlorofluorescein (DCF). The fluorescence intensity of DCF is proportional to the amount of ROS produced by cells. After $1 \times 10^{5}$ cells/well of SKOV3 and SKOV3/DDP cells were seeded on a 6-well plate for $24 \mathrm{~h}$, the cells were treated with cisplatin $(1,10 \mu \mathrm{M})$ or $\mathrm{H}_{2} \mathrm{O}_{2}(0.1,1 \mathrm{mM})$ for $1 \mathrm{~h}$. In brief, the cells were pre-treated with cisplatin or $\mathrm{H}_{2} \mathrm{O}_{2}$ for $1 \mathrm{~h}$ for the production of ROS. Data analysis was performed with CellQuest ${ }^{\mathrm{TM}}$ software and the mean fluorescence intensity was used to quantify the results.

Statistical analysis. Data are expressed as the mean \pm standard deviation (SD). Data were analyzed with the SPSS 17.0 software and tested by the one-way analysis of variance (ANOVA). P-values of $\mathrm{P}<0.05$ were defined as indicating a statistically significant result.

\section{Results}

SKOV3/DDP cells display tolerance to TRAIL exposure. To study the TRAIL tolerance in ovarian cancer cells, the cell viability of the ovarian cancer cell lines was examined after treatment with TRAIL at different concentrations $(0,10,50$, $100,250,500$, and $1,000 \mathrm{ng} / \mathrm{ml}$ ) for $48 \mathrm{~h}$, respectively. TRAIL exposure was found to significantly inhibit the viability of the SKOV3 cells, which successively decreased with an increasing TRAIL concentration from $1.00 \pm 0.00$ down to $0.55 \pm 0.15$. The cell viability of the SKOV3/DDP cells, in contrast, successively increased upon treatment with increasing concentrations of TRAIL from $1.00 \pm 0.00$ to $1.91 \pm 0.22$ (Fig. 1A). The viability of the SKOV3/DDP cells was significantly higher compared with the SKOV3 cells upon treatment with the same concentration of TRAIL $(\mathrm{P}<0.01, \mathrm{P}<0.001, \mathrm{n}=3)$. 
A

TRAIL $48 \mathrm{~h}$
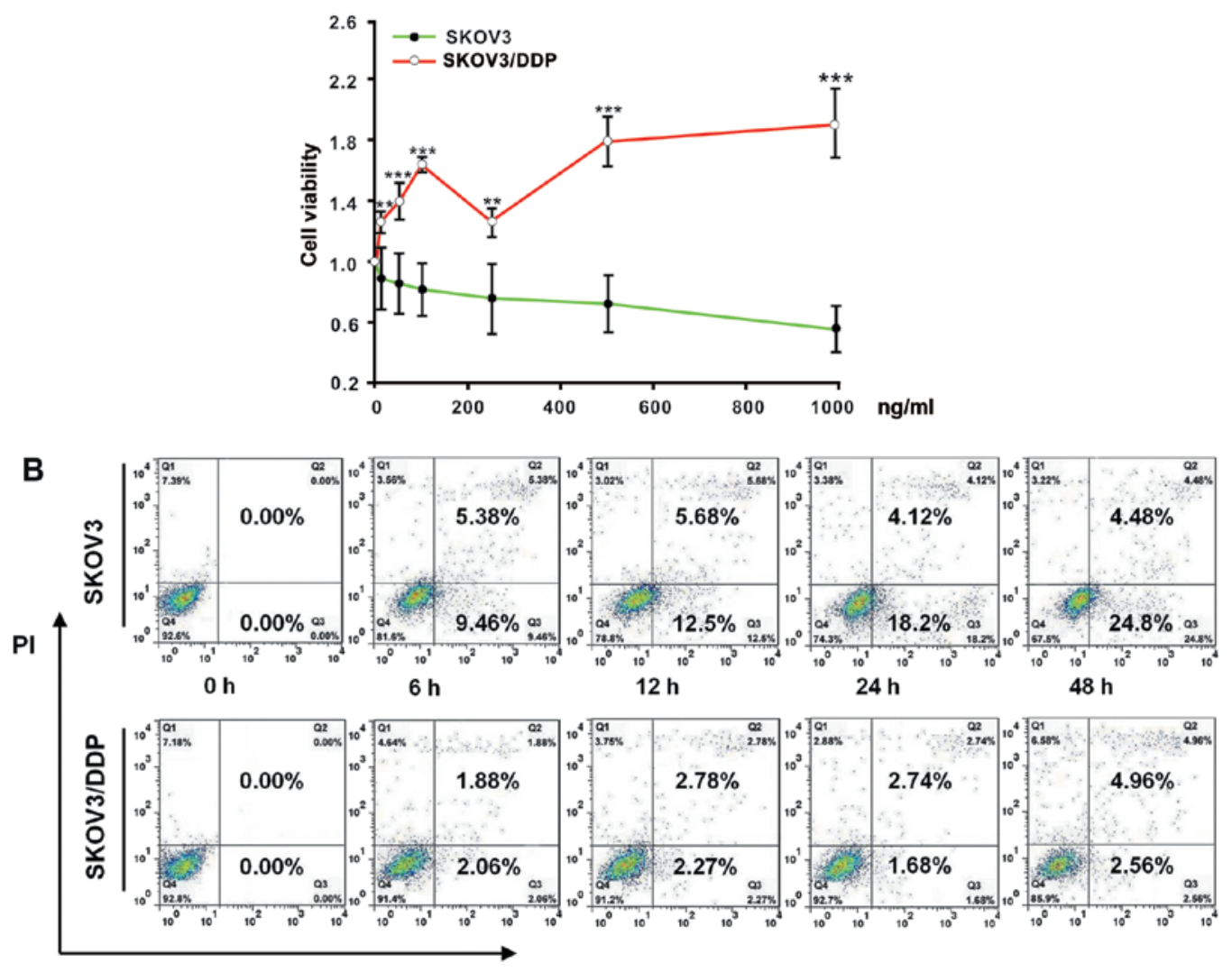

FITC Annexin V

Figure 1. SKOV3/DDP cells display tolerance under TRAIL exposure. (A) Measurements of the cell viability with the MTT assay. SKOV3 and SKOV3/DDP cells were treated for $48 \mathrm{~h}$ with increasing concentrations of TRAIL $(0,10,50,100,250,500$ and 1,000 ng/ml). All assays were performed in triplicate and repeated three times. The data are expressed as the mean \pm SEM of triplicate samples $\left({ }^{* *} \mathrm{P}<0.01,{ }^{* * * *} \mathrm{P}<0.001\right.$, compared with the SKOV 3 cells under treatment with the same concentration of TRAIL). The percentage of cell viability was defined as the relative absorbance of treated vs. untreated cells. (B) Flow cytometric analysis of cell apoptosis. SKOV3 and SKOV3/DDP cells were incubated with $500 \mathrm{ng} / \mathrm{ml}$ of TRAIL for the indicated times $(0,6,12,24$, and $48 \mathrm{~h})$. Next, the cells were harvested, washed with PBS, and stained with FITC-Annexin V and propidium iodide (PI). Data were analyzed using CellQuest ${ }^{\mathrm{TM}}$ software.

Furthermore, the cell apoptosis levels were analyzed after treatment with TRAIL $(500 \mathrm{ng} / \mathrm{ml})$ in a time-dependent manner. The SKOV3/DDP cells exhibited a lower apoptosis level after TRAIL treatment than the SKOV3 cells (Fig. 1B). This finding agrees with the TRAIL tolerance of SKOV3/DDP cells, which was absent in the SKOV3 cells.

Low dose of cisplatin leads to the development of TRAIL tolerance in SKOV3 cells. To ascertain whether TRAIL tolerance is induced by cisplatin due to chemotherapeutic failure, we pretreated SKOV3 cells with two different concentrations of cisplatin $(1$ or $10 \mu \mathrm{M})$ for $1 \mathrm{~h}$ before the cells were treated with $(500 \mathrm{ng} / \mathrm{ml})$ TRAIL or without for another $24 \mathrm{~h}$. Measuring the cell viability revealed that pretreatment with the higher concentration of cisplatin $(10 \mu \mathrm{M})$ inhibited, but pretreatment with the lower cisplatin concentration $(1 \mu \mathrm{M})$ promoted the growth of SKOV3 cells upon TRAIL treatment. For example, the percentage of cell viability (defined as the relative absorbance of the treated vs. the untreated cells) was $97.40 \pm 6.09$ in the cells that were treated with a low cisplatin concentration of $1 \mu \mathrm{M}$, whereas it was $59.26 \pm 2.75$ in the cells that were treated with a high cisplatin concentration of $10 \mu \mathrm{M}$. The same tendency was observed in the SKOV3 cells that were treated with TRAIL. Cells that were treated with TRAIL only revealed a cell viability of $87.15 \pm 11.20 \%$. Pretreatment with a high cisplatin concentration of $10 \mu \mathrm{M}$ reduced the cell viability to $37.67 \pm 1.18 \%$, whereas pretreatment with a low cisplatin concentration of $1 \mu \mathrm{M}$ increased the cell viability to $125.11 \pm 6.29 \%$ (Fig. 2A). Comparing the cell apoptosis levels under the same culture conditions demonstrated that a high dose of cisplatin promoted TRAIL-induced apoptosis, while a low dose of cisplatin nearly completely inhibits TRAIL-mediated apoptosis (Fig. 2B). These results indicate that a high dose of cisplatin possibly cooperates with TRAIL to kill the SKOV3 cells, while a low dose of cisplatin renders the SKOV3 cells tolerant to TRAIL.

Lower levels of oxidative stress promote TRAIL tolerance in SKOV3 cells. To study the impact of oxidative stress on the cisplatin-mediated TRAIL tolerance in SKOV3 cells, we first examined whether cisplatin induces an increase in the intracellular ROS levels. The same amounts of ovarian cancer cells were treated for $1 \mathrm{~h}$ with cisplatin $(1$ or $10 \mu \mathrm{M})$, or alternatively with $\mathrm{H}_{2} \mathrm{O}_{2}(0.1$ or $1 \mathrm{mM})$ as a positive control. Intracellular ROS levels were measured by CM- $\mathrm{H}_{2}$ DCFDA staining and FACS analysis. Interestingly, ROS levels in the SKOV3/DDP cells were generally much higher than levels in the SKOV3 cells. We determined a relative fluorescence intensity of ROS 


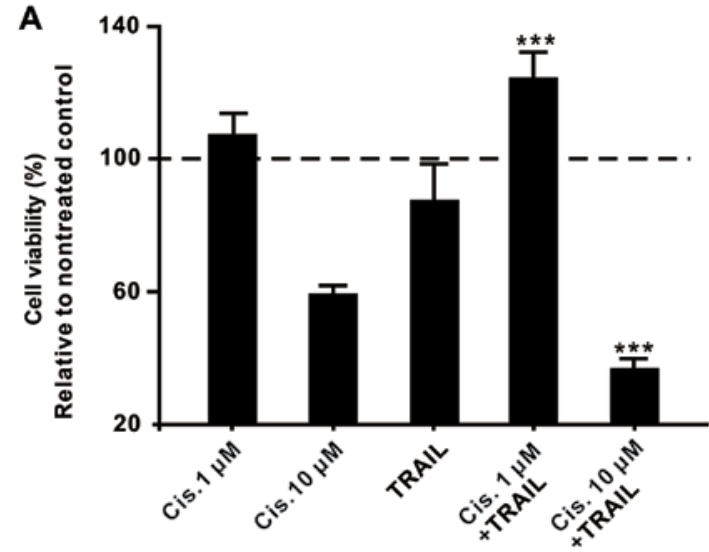

B

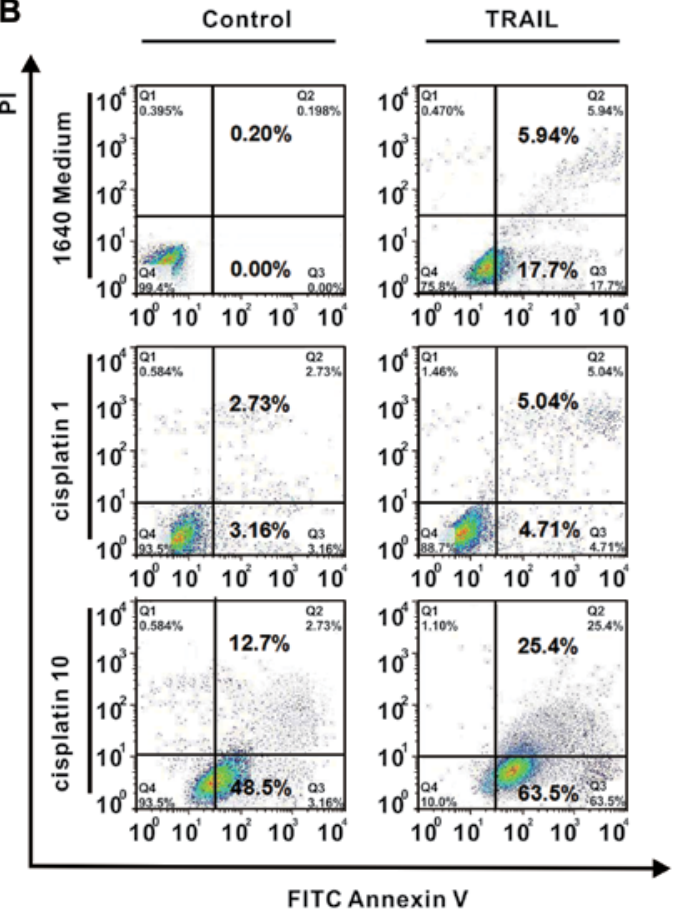

Figure 2. Low dose of cisplatin causes TRAIL tolerance in SKOV3 cells. (A) Measurements of the cell viability with the MTT assay. SKOV3 cells were pretreated with cisplatin $(0,1$, or $10 \mu \mathrm{M})$ for $1 \mathrm{~h}$ and then treated without or with TRAIL $(500 \mathrm{ng} / \mathrm{ml})$ for another $24 \mathrm{~h}$. All assays were performed in triplicate and repeated three times. The data are expressed as the mean \pm SEM of triplicate samples $\left({ }^{* * *} \mathrm{P}<0.001\right.$, compared with the TRAIL groups). The percentage of cell viability was defined as the relative absorbance of treated vs. untreated cells. (B) Flow cytometric analysis of cell apoptosis. SKOV3 cells were pretreated with cisplatin $(0,1$, or $10 \mu \mathrm{M})$ for $1 \mathrm{~h}$ and then treated without or with TRAIL $(500 \mathrm{ng} / \mathrm{ml})$ for another $24 \mathrm{~h}$. Next, the cells were harvested, washed with PBS, and stained with FITC-Annexin V and propidium iodide (PI). Data were analyzed using CellQuest ${ }^{\mathrm{TM}}$ software.

in the SKOV3/DDP control group of 193.6 \pm 8.2 , whereas the SKOV3 control group only exhibited a value of $23.7 \pm 3.2$ $(\mathrm{P}<0.001, \mathrm{n}=3)$. Furthermore, we observed a dose-dependent increase in the intracellular ROS levels upon cisplatin and $\mathrm{H}_{2} \mathrm{O}_{2}$ treatment in both the SKOV3 and SKOV3/DDP cells. The relative fluorescence intensity of ROS in the SKOV3 cells that had been treated with $1 \mu \mathrm{M}$ of cisplatin was $48.3 \pm 4.7$, whereas treatment with a higher concentration of cisplatin $(10 \mu \mathrm{M})$ resulted in a 3 -fold higher value of $156.3 \pm 5.6$. The same effect was observed for $\mathrm{H}_{2} \mathrm{O}_{2}$, which yielded a value of only $55.7 \pm 7.7$ upon treatment with $0.1 \mathrm{mM} \mathrm{H}_{2} \mathrm{O}_{2}$, whereas treatment with
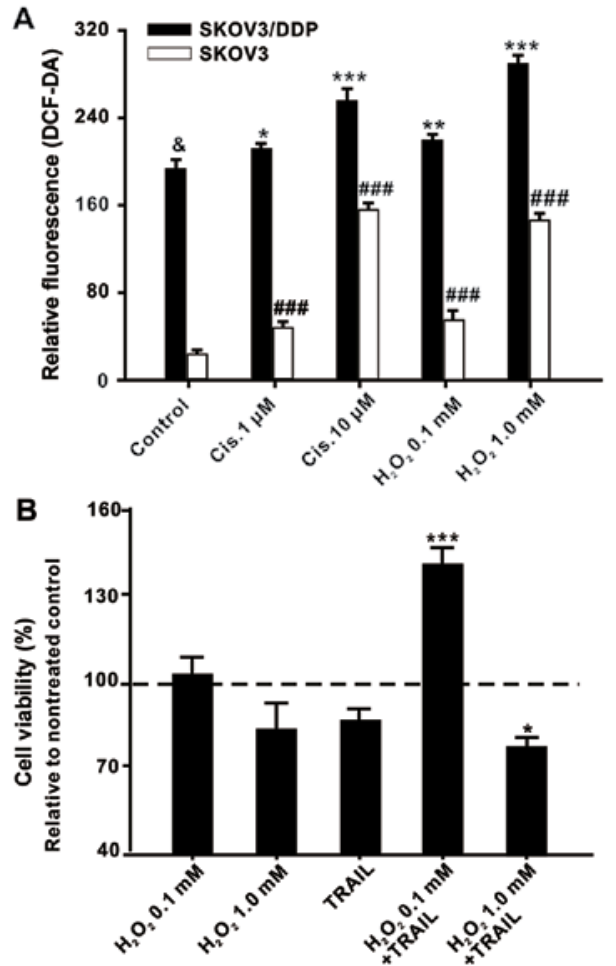

C

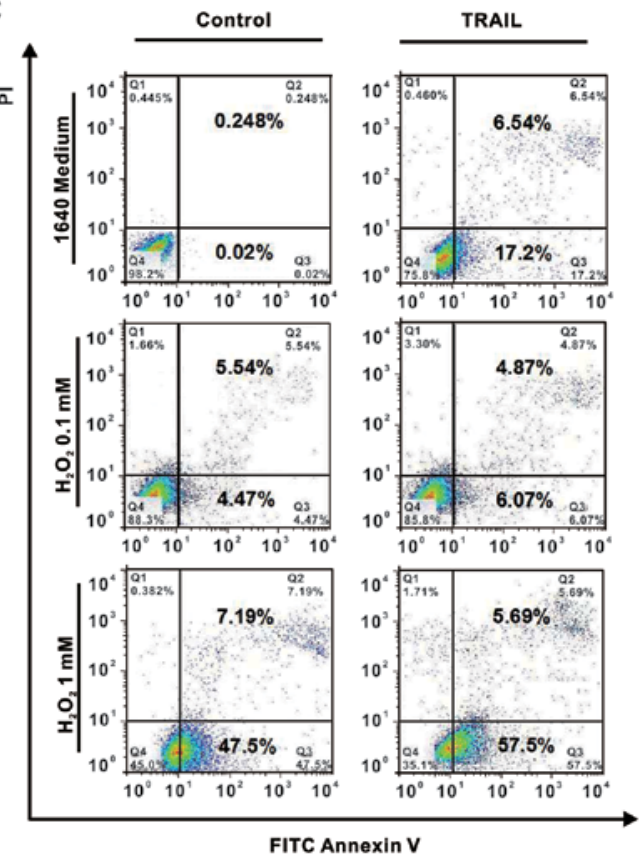

Figure 3. Cisplatin-induced mild oxidative stress promotes TRAIL tolerance in SKOV3 cells. (A) CM- $\mathrm{H}_{2}$ DCFDA staining and FACS analysis of the intracellular ROS levels in SKOV3 or SKOV3/DDP cells. The same amounts of SKOV3 or SKOV3/DDP cells $\left(1 \times 10^{5}\right)$ were treated with different concentrations of cisplatin $(1$ or $10 \mu \mathrm{M})$ or $\mathrm{H}_{2} \mathrm{O}_{2}(0.1$ or $1 \mathrm{mM})$ for $1 \mathrm{~h}$. All assays were performed in triplicate and repeated three times. The data are expressed as the mean \pm SEM of triplicate samples $\left({ }^{*} \mathrm{P}<0.05,{ }^{* *} \mathrm{P}<0.01,{ }^{*}{ }^{* * *} \mathrm{P}<0.001\right.$, compared with the control SKOV3/DDP cells; ${ }^{\circledR} \mathrm{P}<0.001,{ }^{\# \# \#} \mathrm{P}<0.001$, compared with the control SKOV3 cells). (B) Measurement of the cell viability with the MTT assay. SKOV3 cells were pretreated with $\mathrm{H}_{2} \mathrm{O}_{2}(0.1$ or $1 \mathrm{mM})$ for $1 \mathrm{~h}$ and then treated without or with TRAIL $(500 \mathrm{ng} / \mathrm{ml})$ for $24 \mathrm{~h}$. All assays were performed in triplicate and repeated three times. The data are expressed as the mean \pm SEM of triplicate samples $\left({ }^{*} \mathrm{P}<0.05,{ }^{* * *} \mathrm{P}<0.001\right.$, compared with the TRAIL group). The percentage of cell viability was defined as the relative absorbance of treated vs. untreated cells. (C) Flow cytometric analysis of cell apoptosis. SKOV3 cells were pretreated with $\mathrm{H}_{2} \mathrm{O}_{2}(0.1$ or $1 \mathrm{mM})$ for $1 \mathrm{~h}$ and then treated without or with TRAIL $(500 \mathrm{ng} / \mathrm{ml})$ for $24 \mathrm{~h}$. Next, the cells were harvested, washed with PBS, and stained with FITC-Annexin V and propidium iodide (PI). Data were analyzed using CellQuest ${ }^{\mathrm{TM}}$ software. 

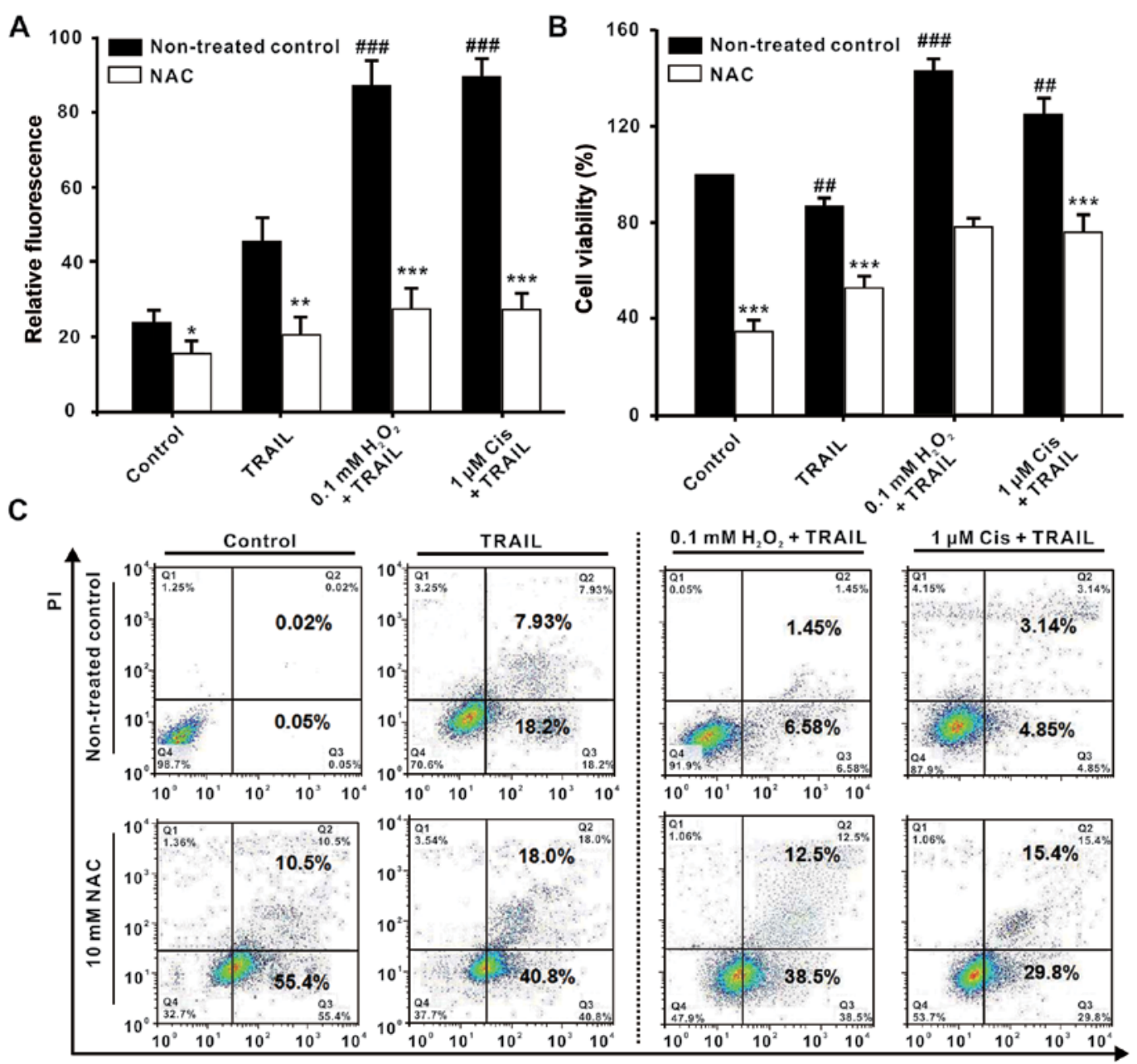

FITC Annexin V

Figure 4. Oxidative stress regulation reverses the TRAIL tolerance in SKOV3 cells. After pretreatment without or with $N$-acetyl-cysteine (NAC) $(0,10 \mathrm{mM})$ for $1 \mathrm{~h}$, the SKOV3 cells were treated with cisplatin $(1 \mu \mathrm{M})$ or $\mathrm{H}_{2} \mathrm{O}_{2}(0.1 \mathrm{mM})$. One hour later, the cells were treated together with TRAIL $(500 \mathrm{ng} / \mathrm{ml})$ for another $24 \mathrm{~h}$. (A) CM- $\mathrm{H}_{2}$ DCFDA staining and FACS analysis of the intracellular ROS levels in the SKOV3/DDP cells. (B) Measurement of the cell viability with the MTT assay. The percentage of cell viability was defined as the relative absorbance of treated vs. untreated cells. (C) Flow cytometric analysis of cell apoptosis SKOV3 cells were harvested, washed with PBS, and stained with FITC-Annexin V and propidium iodide (PI). Data were analyzed using CellQuest ${ }^{\mathrm{TM}}$ software. All assays were performed in triplicate and repeated three times. The data are expressed as the mean \pm SEM of triplicate samples $\left({ }^{\#} \mathrm{P}<0.05,{ }^{\# \# \#} \mathrm{P}<0.001\right.$, compared with the control groups; ${ }^{* *} \mathrm{P}<0.05,{ }^{* *} \mathrm{P}<0.01,{ }^{* * *} \mathrm{P}<0.001$, compared with the 1640 medium groups, respectively).

the higher $\mathrm{H}_{2} \mathrm{O}_{2}$ concentration of $1 \mathrm{mM}$ led to a nearly 3 -fold higher relative fluorescence intensity of ROS of $147.6 \pm 5.2$. The same tendency was observed for the SKOV3/DDP cells, which revealed lower relative fluorescence intensities of ROS of $212.0 \pm 2.6$ or $220.0 \pm 5.1$ upon treatment with a low concentration of cisplatin $(1 \mu \mathrm{M})$ or $\mathrm{H}_{2} \mathrm{O}_{2}(0.1 \mathrm{mM})$, respectively. Treatment with a higher concentration of cisplatin $(10 \mu \mathrm{M})$ or $\mathrm{H}_{2} \mathrm{O}_{2}(1 \mathrm{mM})$ increased the values to $256.3 \pm 10.3$ or $288.3 \pm 9.1$, respectively, although this increase was not as marked as the increase observed for the SKOV3 cells (Fig. 3A).

Subsequently, the cell viability was measured with the MTT assay and the cell apoptosis was analyzed by the FACS method. Therefore, the SKOV3 cells were pretreated with $\mathrm{H}_{2} \mathrm{O}_{2}(0.1$ or $1 \mathrm{mM})$ for $1 \mathrm{~h}$ and then treated with or without TRAIL (500 ng/ml) for $24 \mathrm{~h}$. As shown in Fig. 3B, the percentage of cell viability was similar for the cells treated with TRAIL $(87.15 \pm 11.20)$ and those that had been treated with a high concentration of $\mathrm{H}_{2} \mathrm{O}_{2}(1 \mathrm{mM})$ plus TRAIL $(81.35 \pm 5.11)$, whereas cells that had been treated with a low concentration of $\mathrm{H}_{2} \mathrm{O}_{2}(0.1 \mathrm{mM})$ plus TRAIL revealed a significantly higher cell viability of $142.72 \pm 5.33 \%$ (Fig. 3B). In agreement with this, a high dose of $\mathrm{H}_{2} \mathrm{O}_{2}$ was found to promote the apoptosis caused by TRAIL, while a low dose of $\mathrm{H}_{2} \mathrm{O}_{2}$ inhibited TRAIL-induced apoptosis (Fig. 3C). These results revealed that the TRAIL tolerance of SKOV3 cells developed upon treatment with a low dose of $\mathrm{H}_{2} \mathrm{O}_{2}(0.1 \mathrm{mM})$, whereas treatment with a high dose of $\mathrm{H}_{2} \mathrm{O}_{2}(1 \mathrm{mM})$ improved the TRAIL sensitivity in the SKOV3 cells. This suggests that lower levels of oxidative stress are associated with TRAIL tolerance in SKOV3 cells.

NAC reverses the cisplatin-induced TRAIL tolerance in SKOV3 cells. Next, we aimed to investigate whether the cisplatin-induced oxidative stress can modulate TRAIL-induced apoptosis. To this goal, we studied the impact of the oxidative stress scavenger $N$-acetyl-cysteine (NAC), which is expected to inhibit the ROS production in the SKOV3 cells. Therefore, the cells were pretreated with NAC in addition to cisplatin $(1 \mu \mathrm{M})$ 
or $\mathrm{H}_{2} \mathrm{O}_{2}(0.1 \mathrm{mM})$, respectively, and the relative fluorescence intensity of ROS as well as the cell viability were analyzed. The results were compared with the respective control cells pretreated with cisplatin $(1 \mu \mathrm{M})$ or $\mathrm{H}_{2} \mathrm{O}_{2}(0.1 \mathrm{mM})$, but without the addition of NAC. Cells that had been treated with NAC, $\mathrm{H}_{2} \mathrm{O}_{2}$ and TRAIL exhibited a relative fluorescence intensity of ROS of $27.6 \pm 5.8$, which was much lower than the value of $87.5 \pm 6.5$ of the control group that had not been treated with NAC. The additional NAC pretreatment of the cisplatin and TRAIL-treated cells also decreased the relative fluorescence intensity of ROS with respect to the control group. The cisplatin and TRAIL-treated control group exhibited a value of $89.6 \pm 5.3$, whereas the cells that had been additionally pretreated with NAC exhibited a significantly lower value of 26.3 \pm 5.3 (Fig. 4A). In conclusion, pretreatment with NAC significantly inhibited the ROS increase induced by cisplatin $(1 \mu \mathrm{M})$ or $\mathrm{H}_{2} \mathrm{O}_{2}(0.1 \mathrm{mM})$.

Consistent with these findings, NAC pretreatment furthermore inhibited the viability of the SKOV3 cells. Control cells that had been treated with $\mathrm{H}_{2} \mathrm{O}_{2}$ and TRAIL revealed a cell viability of $142.72 \pm 5.33 \%$, whereas cells that had additionally been treated with NAC exhibited a lower cell viability of $78.56 \pm 3.21 \%$. Analogously, the cell viability of cells that had been treated with NAC, cisplatin, and TRAIL was lower $(76.25 \pm 7.24 \%)$ than that of the corresponding control group that had been treated with cisplatin and TRAIL only, which exhibited a cell viability of $125.18 \pm 6.63 \%$ (Fig. 4B). These results were corroborated by flow cytometric analysis of cell apoptosis (Fig. 4C), which revealed that NAC abrogated the inhibition of the TRAIL-induced apoptosis mediated by a low dose of cisplatin or $\mathrm{H}_{2} \mathrm{O}_{2}$ by acting as a scavenger of ROS that had been produced by cisplatin or $\mathrm{H}_{2} \mathrm{O}_{2}$. Therefore, these results confirm the cisplatin-induced generation of low levels of intracellular ROS as the causative mechanism of TRAIL tolerance in SKOV3 cells.

The tolerance of TRAIL in SKOV3/DDP cells is dependent on oxidative stress. As mentioned above, the ROS levels of SKOV3/DDP cells were generally much higher than those of the SKOV3 cells. Whether the regulation of oxidative stress could reverse the TRAIL tolerance in SKOV3/DDP cells was investigated. NAC was used to inhibit the ROS production in the SKOV3/DDP cells. When NAC was used at a concentration of $10 \mathrm{mM}$, the relative fluorescence intensity of ROS decreased from $190.5 \pm 7.2$ in the untreated control group to $170.0 \pm 5.6$ in the cells that were additionally treated with NAC, and the relative fluorescence intensity of ROS decreased from 203.0 3 3.2 in the TRAIL-treated control group to $184.0 \pm 4.5$ in the cells that were additionally treated with NAC (Fig. 5A). Contrary to our expectations, NAC $(10 \mathrm{mM})$ only slightly increased the TRAIL-induced apoptosis of the SKOV3/DDP cells (Fig. 5B).

When NAC was increased to $40 \mathrm{mM}$ to further decrease ROS in the SKOV3/DDP cells, the relative fluorescence intensity of ROS in the cells that were additionally treated with NAC was inhibited by $74.8 \pm 4.5 \%$ compared with that in the untreated control group, and the relative fluorescence intensity of ROS in the cells that were additionally treated with NAC was inhibited $70.5 \pm 3.8 \%$ compared with that in the TRAIL-treated control group (Fig. 5A). Ultimately, NAC ( $40 \mathrm{mM})$ significantly increased the TRAIL-induced apoptosis of the SKOV3/DDP

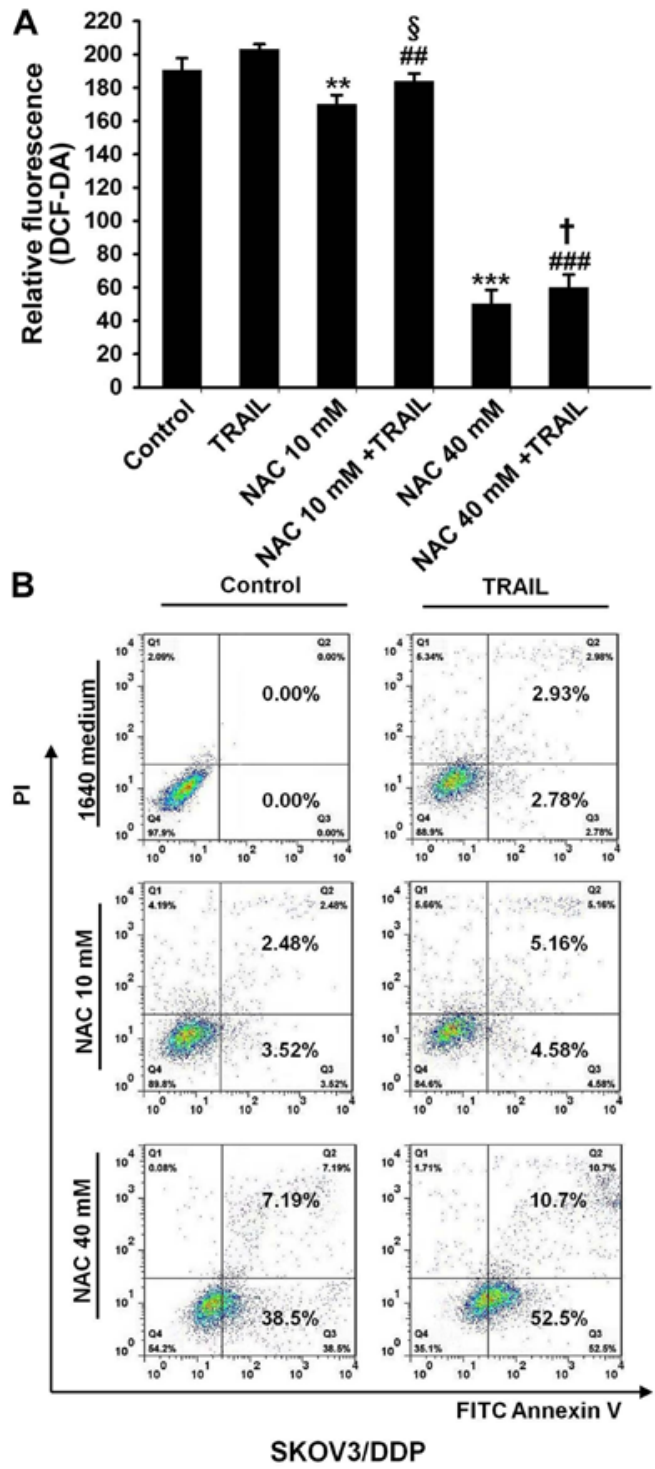

Figure 5. The development of TRAIL tolerance in SKOV3/DDP cells is dependent on oxidative stress. (A) $\mathrm{CM}-\mathrm{H}_{2} \mathrm{DCFDA}$ staining and FACS analysis of the intracellular ROS levels in SKOV3/DDP cells. SKOV3-DDP cells were pretreated with the oxidative stress scavenger $\mathrm{N}$-acetyl-cysteine (NAC) $(0,10$, and $40 \mathrm{mM})$ for $1 \mathrm{~h}$ and then the cells were treated without or with TRAIL $(500 \mathrm{ng} / \mathrm{ml})$ for $24 \mathrm{~h}$. All assays were performed in triplicate and repeated three times. The data are expressed as the mean \pm SEM of triplicate samples $\left[{ }^{* *} \mathrm{P}<0.01,{ }^{* * *} \mathrm{P}<0.001\right.$, compared with the control groups; ${ }^{\# \#} \mathrm{P}<0.01$,

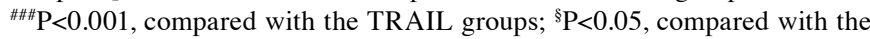
NAC $(10 \mathrm{mM})$ groups; ${ }^{\dagger} \mathrm{P}<0.05$, compared with the NAC $(40 \mathrm{mM})$ groups]. (B) Flow cytometric analysis of cell apoptosis. SKOV3-DDP cells were pretreated with the oxidative stress scavenger NAC $(10$, and $40 \mathrm{mM})$ for $1 \mathrm{~h}$ and then treated without or with TRAIL $(500 \mathrm{ng} / \mathrm{ml})$ for another $24 \mathrm{~h}$. Then, the cells were harvested, washed with PBS, and stained with FITC-Annexin V and propidium iodide (PI). Data were analyzed using CellQuest ${ }^{\mathrm{TM}}$ software.

cells (Fig. 5B). Taken together, we conclude that the development of TRAIL tolerance in SKOV3/DDP cells was at least partially dependent on oxidative stress.

\section{Discussion}

TRAIL belongs to a class of cytokines and displays specific anticancer activity against a wide range of cancer cells without showing significant side effects (1-3). However, TRAIL 
tolerance is still a potential limitation in the treatment of cisplatin-resistant ovarian cancer. In the present study, we confirmed that SKOV3/DDP cells are tolerant to TRAIL, that a low dose of cisplatin produces TRAIL tolerance in SKOV3 cells, and that cisplatin-induced oxidative stress modulates TRAIL-induced apoptosis. These observations suggest that the regulation of cisplatin-induced oxidative stress may be a promising new treatment strategy for improving TRAIL tolerance in cisplatin-resistant epithelial ovarian cancer.

Chemotherapeutic agents are an important means of adjuvant therapy for the treatment of patients with ovarian cancer. For example, combination therapy using cisplatin and paclitaxel is considered to be the gold standard of chemotherapy (7). The antitumor effect of cisplatin has been ascribed to its binding to the DNA double-helix at the N7 atoms of guanine bases. This binding prevents the strands from uncoiling and separating and results ultimately in cellular apoptosis (28-30). A major drawback, however, is the development of drug resistance, where a low dose of cisplatin may be one of the important reasons. For example, cisplatin can bind to plasma proteins, such as human serum albumin, and has poor solubility $(31,32)$. In addition, high interstitial fluid pressure in solid tumors including epithelial ovarian cancer provokes vascular tortuosity and leakage, which makes it difficult for chemotherapeutic agents to penetrate into the depth of the tumor $(33,34)$. These undesirable effects may limit the availability of cisplatin at lower concentrations. In addition, cisplatin-resistant cell lines of human ovarian cancer have been derived from cisplatin-sensitive cell lines by repeated exposure to low but continuously increasing concentrations of cisplatin (35). In the present study, a low dose of cisplatin $(1 \mu \mathrm{M})$, but not a high dose of cisplatin $(10 \mu \mathrm{M})$ caused TRAIL tolerance in the SKOV3 cells. These results explain why a low dose of cisplatin produces cisplatin resistance in ovarian cancer, where TRAIL tolerance in cisplatin may be one of the reasons.

In general, it is difficult to give a general definition for the levels of oxidative stress. In the present study, low doses of cisplatin $(1 \mu \mathrm{M})$ or $\mathrm{H}_{2} \mathrm{O}_{2}(0.1 \mathrm{mM})$ produced a lower level of ROS, which we regarded as mild oxidative stress, while higher doses of cisplatin $(10 \mu \mathrm{M})$ or $\mathrm{H}_{2} \mathrm{O}_{2}(1 \mathrm{mM})$ induced a higher level of ROS, which we considered as high oxidative stress. Thereby, the two different levels of oxidative stress provoked contrary effects, as mild oxidative stress promotes cell proliferation, whereas serious oxidative stress induces cell apoptosis. For example, mild oxidative stress induced by cisplatin $(1 \mu \mathrm{M})$ or $\mathrm{H}_{2} \mathrm{O}_{2}(1 \mathrm{mM})$ increased the viability of the SKOV3 cells and inhibited cell apoptosis. In contrast, serious oxidative stress induced by higher concentrations of cisplatin $(1 \mu \mathrm{M})$ or $\mathrm{H}_{2} \mathrm{O}_{2}(1 \mathrm{mM})$ decreased SKOV3 cell viability and significantly promoted cell apoptosis. In addition, high doses of cisplatin $(10 \mu \mathrm{M})$ or $\mathrm{H}_{2} \mathrm{O}_{2}(1 \mathrm{mM})$ enhanced the chemotherapeutic effect of TRAIL in SKOV3 cells, while a combination of TRAIL and a low dose of cisplatin $(1 \mu \mathrm{M})$ or $\mathrm{H}_{2} \mathrm{O}_{2}(0.1 \mathrm{mM})$ enhanced the proliferation of SKOV3 cells much more than treatment only with a low dose of cisplatin $(1 \mu \mathrm{M})$ or $\mathrm{H}_{2} \mathrm{O}_{2}(0.1 \mathrm{mM})$. Our results corroborate previous studies that showed that different levels of oxidative stress determine cancer cell fate (11-14). In addition, the impact of TRAIL on cells is associated with differences in the expres- sion of TRAIL receptors, such as DR4, DR5, DcR1, Dcr2 and $\mathrm{OPG}$, on the surface of ovarian cancer cells. A recent review demonstrated that following ligand binding, the TRAIL death receptors DR4 and DR5 are able to induce cell death (apoptosis or necroptosis). Alternatively, these receptors may also enhance cell proliferation, inflammation, migration and invasion via activation of multiple 'non-death-inducing' signal transduction pathways (36). The mechanisms of TRAIL tolerance production may be complex and require further investigation. However, these findings suggest that mild oxidative stress induced by a low dose of cisplatin may be one of the mechanisms producing cisplatin resistance including TRAIL tolerance, and TRAIL tolerance in cisplatin-resistant ovarian cancer cells may be associated with mild oxidative stress.

Furthermore, to identify whether mild oxidative stress modulates TRAIL-induced apoptosis, cells were pretreated with oxidative stress scavenger NAC to inhibit ROS production in the SKOV3 and SKOV3/DDP cells. This revealed that NAC improved the sensitivity of TRAIL in the SKOV3 cells following treatment with a low dose of cisplatin $(1 \mu \mathrm{M})$ or $\mathrm{H}_{2} \mathrm{O}_{2}(0.1 \mathrm{mM})$. Contrary to our expectations, NAC $(10 \mathrm{mM})$ only slightly increased the TRAIL-induced apoptosis of SKOV3/DDP cells and could not completely combat the TRAIL tolerance induced by mild oxidative stress. Next, the treatment of NAC was increased to $40 \mathrm{mM}$ to further decrease ROS in the SKOV3/DDP cells. As a result, NAC (40 $\mathrm{mM}$ ) significantly increased the TRAIL-induced apoptosis of SKOV3/DDP cells. As the ROS levels of the SKOV3/DDP cells were generally much higher than those of the SKOV3 cells, it was more difficult to combat apoptosis in the SKOV3/DDP cells than that in the SKOV3 cells by oxidative stress regulation. Interesting, the ROS levels in the SKOV3/DDP cell groups treated with NAC together with TRAIL were higher compared with the NAC groups, while the apoptosis of the former group was much higher than the latter group. According to our knowledge, there are at least three types of sources for the production of oxidative stress such as the mitochondrium, NADPH oxidase, and the endoplasmic reticulum $(37,38)$. NAC is a thiol-containing compound which reduces the reactive oxygen intermediate $\mathrm{H}_{2} \mathrm{O}_{2}$ and protects against toxic effects. Moreover, other unknown mechanism may be involved in the cisplatin-induced TRAIL tolerance of SKOV3/DDP cells besides oxidative stress.

In summary, we demonstrated that cisplatin evokes oxidative stress in SKOV3 cells, that the SKOV3/DDP cells are tolerant to TRAIL, and that the mild oxidative stress induced by a low dose of cisplatin contributes to the tolerance of TRAIL in SKOV3 cells. Thus, regulation of oxidative stress in order to improve the therapeutic efficacy of TRAIL may be a new treatment strategy for patients with cisplatin-resistant epithelial ovarian cancer.

\section{Acknowledgements}

This study was supported by the Natural Science Foundation of China (grant no. 8117245/H1621), the Outstanding Medical Academic Leader Program of Hubei Province, and Hubei Province Health and Family Planning Scientific Research Project (WJ2015Q044). 


\section{References}

1. Kimberley FC and Screaton GR: Following a TRAIL: Update on a ligand and its five receptors. Cell Res 14: 359-372, 2004.

2. Bernard D, Quatannens B, Vandenbunder B and Abbadie C: $\mathrm{Rel} / \mathrm{NF}-\mathrm{kappaB}$ transcription factors protect against tumor necrosis factor (TNF)-related apoptosis-inducing ligand (TRAIL)-induced apoptosis by up-regulating the TRAIL decoy receptor DcR1. J Biol Chem 276: 27322-27328, 2001.

3. Wiley SR, Schooley K, Smolak PJ, Din WS, Huang CP, Nicholl JK, Sutherland GR, Smith TD, Rauch C, Smith CA, et al Identification and characterization of a new member of the TNF family that induces apoptosis. Immunity 3: 673-682, 1995.

4. Li X, Ling V and Li PC: Same-single-cell analysis for the study of drug efflux modulation of multidrug resistant cells using a microfluidic chip. Anal Chem 80: 4095-4102, 2008.

5. Mundhenke C, Weigel MT, Sturner KH, Roesel F, Meinhold-Heerlein I, Bauerschlag DO, Schem C, Hilpert F Jonat W and Maass N: Novel treatment of ovarian cancer cell lines with imatinib mesylate combined with paclitaxel and carboplatin leads to receptor-mediated antiproliferative effects. J Cancer Res Clin Oncol 134: 1397-1405, 2008.

6. Seeber LM and van Diest PJ: Epigenetics in ovarian cancer. Methods Mol Biol 863: 253-269, 2012.

7. Yi C, Zhang L, Li L, Liu X, Ling S, Zhang F and Liang W: Establishment of an orthotopic transplantation tumor model in nude mice using a drug-resistant human ovarian cancer cell line with a high expression of c-Kit. Oncol Lett 8: 2611-2615, 2014.

8. Belotte J, Fletcher NM, Awonuga AO, Alexis M, Abu-Soud HM, Saed MG, Diamond MP and Saed GM: The role of oxidative stress in the development of cisplatin resistance in epithelial ovarian cancer. Reprod Sci 21: 503-508, 2014.

9. Fatima S, Al-Mohaimeed N, Arjumand S, Banu N, Al-Jameil N and Al-Shaikh Y: Effect of pre- and post-combined multidoses of epigallocatechin gallate and coenzyme Q10 on cisplatin-induced oxidative stress in rat kidney. J Biochem Mol Toxicol 29: 91-97, 2015.

10. Lin L, Zheng J, Zhu W and Jia N: Nephroprotective effect of gelsemine against cisplatin-induced toxicity is mediated via attenuation of oxidative stress. Cell Biochem Biophys 71: 535-541, 2015

11. Huang C, Han Y, Wang Y, Sun X, Yan S, Yeh ET, Chen Y, Cang H, $\mathrm{Li} \mathrm{H}$, Shi G, et al: SENP3 is responsible for HIF-1 transactivation under mild oxidative stress via p300 de-SUMOylation. EMBO J 28: 2748-2762, 2009.

12. López-Lázaro M: Dual role of hydrogen peroxide in cancer: Possible relevance to cancer chemoprevention and therapy. Cancer Lett 252: 1-8, 2007.

13. Suzuki-Karasaki Y, Suzuki-Karasaki M, Uchida M and Ochiai T: Depolarization controls TRAIL-sensitization and tumor-selective killing of cancer cells: Crosstalk with ROS. Front Oncol 4: 128, 2014

14. Wang $\mathrm{J}$ and Yi J: Cancer cell killing via ROS: To increase or decrease, that is the question. Cancer Biol Ther 7: 1875-1884, 2008

15. Xia C, Meng Q, Liu LZ, Rojanasakul Y, Wang XR and Jiang BH: Reactive oxygen species regulate angiogenesis and tumor growth through vascular endothelial growth factor. Cancer Res 67: 10823-10830, 2007.

16. Chan DW, Liu VW, Tsao GS, Yao KM, Furukawa T, Chan KK and Ngan HY: Loss of MKP3 mediated by oxidative stress enhances tumorigenicity and chemoresistance of ovarian cancer cells. Carcinogenesis 29: 1742-1750, 2008.

17. Shigetomi H, Tsunemi T, Haruta S, Kajihara H, Yoshizawa Y, Tanase Y, Furukawa N, Yoshida S, Sado T and Kobayashi H: Molecular mechanisms linking endometriosis under oxidative stress with ovarian tumorigenesis and therapeutic modalities. Cancer Invest 30: 473-480, 2012.

18. King SM, Quartuccio SM, Vanderhyden BC and Burdette JE: Early transformative changes in normal ovarian surface epithelium induced by oxidative stress require Akt upregulation, DNA damage and epithelial-stromal interaction. Carcinogenesis 34: 1125-1133, 2013.

19. Martinez-Outschoorn UE, Curry JM, Ko YH, Lin Z, Tuluc M, Cognetti D, Birbe RC, Pribitkin E, Bombonati A, Pestell RG, et al: Oncogenes and inflammation rewire host energy metabolism in the tumor microenvironment: RAS and $\mathrm{NFKB}$ target stromal MCT4. Cell Cycle 12: 2580-2597, 2013.
20. Choi K, Ryu SW, Song S, Choi H, Kang SW and Choi C: Caspase-dependent generation of reactive oxygen species in human astrocytoma cells contributes to resistance to TRAIL-mediated apoptosis. Cell Death Differ 17: 833-845, 2010

21. Yi L, Zongyuan Y, Cheng G, Lingyun Z, Guilian Y and Wei G: Quercetin enhances apoptotic effect of tumor necrosis factor-related apoptosis-inducing ligand (TRAIL) in ovarian cancer cells through reactive oxygen species (ROS) mediated CCAAT enhancer-binding protein homologous protein (CHOP)-death receptor 5 pathway. Cancer Sci 105: 520-527, 2014

22. Lee MW, Park SC, Kim JH, Kim IK, Han KS, Kim KY, Lee WB, Jung YK and Kim SS: The involvement of oxidative stress in tumor necrosis factor (TNF)-related apoptosis-inducing ligand (TRAIL)-induced apoptosis in HeLa cells. Cancer Lett 182: 75-82, 2002.

23. Wang J, Jin L, Li X, Deng H, Chen Y, Lian Q, Ge R and Deng H: Gossypol induces apoptosis in ovarian cancer cells through oxidative stress. Mol Biosyst 9: 1489-1497, 2013.

24. Das A, Banik NL and Ray SK: Garlic compounds generate reactive oxygen species leading to activation of stress kinases and cysteine proteases for apoptosis in human glioblastoma T98G and U87MG cells. Cancer 110: 1083-1095, 2007.

25. Lee DH, Rhee JG and Lee YJ: Reactive oxygen species up-regulate p53 and Puma; a possible mechanism for apoptosis during combined treatment with TRAIL and wogonin. Br J Pharmacol 157: 1189-1202, 2009.

26. Powolny AA and Singh SV: Multitargeted prevention and therapy of cancer by diallyl trisulfide and related Allium vegetable-derived organosulfur compounds. Cancer Lett 269: 305-314, 2008

27. Shenoy K, Wu Y and Pervaiz S: LY303511 enhances TRAIL sensitivity of SHEP-1 neuroblastoma cells via hydrogen peroxide-mediated mitogen-activated protein kinase activation and up-regulation of death receptors. Cancer Res 69: 1941-1950, 2009.

28. Pasini A and Zunino F: New cisplatin analogues - on the way to better antitumor agents. Angew Chem Int Ed Engl 26: 615-624, 1987.

29. Poirier MC, Lippard SJ, Zwelling LA, Ushay HM, Kerrigan D, Thill CC, Santella RM, Grunberger D and Yuspa SH: Antibodies elicited against cis-diamminedichloroplatinum(II)-modified DNA are specific for cis-diamminedichloroplatinum(II)-DNA adducts formed in vivo and in vitro. Proc Natl Acad Sci USA 79: 6443-6447, 1982

30. Wong E and Giandomenico CM: Current status of platinum-based antitumor drugs. Chem Rev 99: 2451-2466, 1999.

31. Calderone V, Casini A, Mangani S, Messori L and Orioli PL: Structural investigation of cisplatin-protein interactions: Selective platination of His19 in a cuprozinc superoxide dismutase. Angew Chem Int Ed Engl 45: 1267-1269, 2006.

32. DeConti RC, Toftness BR, Lange RC and Creasey WA: Clinical and pharmacological studies with cis-diamminedichloroplatinum (II). Cancer Res 33: 1310-1315, 1973.

33. Hagendoorn J, Tong R, Fukumura D, Lin Q, Lobo J, Padera TP, Xu L, Kucherlapati R and Jain RK: Onset of abnormal blood and lymphatic vessel function and interstitial hypertension in early stages of carcinogenesis. Cancer Res 66: 3360-3364, 2006.

34. Jain RK: Normalizing tumor vasculature with anti-angiogenic therapy: A new paradigm for combination therapy. Nat Med 7: 987-989, 2001.

35. Behrens BC, Hamilton TC, Masuda H, Grotzinger KR, Whang-Peng J, Louie KG, Knutsen T, McKoy WM, Young RC and Ozols RF: Characterization of a cis-diamminedichloroplatinum(II)-resistant human ovarian cancer cell line and its use in evaluation of platinum analogues. Cancer Res 47: 414-418, 1987.

36. Bertsch U, Röder C, Kalthoff $\mathrm{H}$ and Trauzold A: Compartmentalization of TNF-related apoptosis-inducing ligand (TRAIL) death receptor functions: Emerging role of nuclear TRAIL-R2. Cell Death Dis 5: e1390, 2014.

37. Ashraf NU and Sheikh TA: Endoplasmic reticulum stress and oxidative stress in the pathogenesis of non-alcoholic fatty liver disease. Free Radic Res 49: 1405-1418, 2015.

38. Afanas'ev I: Reactive oxygen species signaling in cancer: Comparison with aging. Aging Dis 2: 219-230, 2011. 